\title{
Structural Damage Detection Based on Modal Parameters Using Continuous Ant Colony Optimization
}

\author{
Aditi Majumdar, ${ }^{1}$ Bharadwaj Nanda, ${ }^{2}$ Dipak Kumar Maiti, ${ }^{1}$ and Damodar Maity ${ }^{3}$ \\ ${ }^{1}$ Department of Aerospace Engineering, Indian Institute of Technology, Kharagpur 721302, India \\ ${ }^{2}$ Department of Civil Engineering, Veer Surendra Sai University of Technology, Burla 768018, India \\ ${ }^{3}$ Department of Civil Engineering, Indian Institute of Technology, Kharagpur 721302, India
}

Correspondence should be addressed to Bharadwaj Nanda; bharadwajnanda@gmail.com

Received 30 May 2014; Revised 3 September 2014; Accepted 3 September 2014; Published 30 September 2014

Academic Editor: Siamak Talatahari

Copyright (C) 2014 Aditi Majumdar et al. This is an open access article distributed under the Creative Commons Attribution License, which permits unrestricted use, distribution, and reproduction in any medium, provided the original work is properly cited.

\begin{abstract}
A method is presented to detect and quantify structural damages from changes in modal parameters (such as natural frequencies and mode shapes). An inverse problem is formulated to minimize the objective function, defined in terms of discrepancy between the vibration data identified by modal testing and those computed from analytical model, which then solved to locate and assess the structural damage using continuous ant colony optimization algorithm. The damage is formulated as stiffness reduction factor. The study indicates potentiality of the developed code to solve a wide range of inverse identification problems.
\end{abstract}

\section{Introduction}

Structural health monitoring (SHM) has become an important area of research within the civil, mechanical, aerospace engineering community in recent years. Damage to structure may be caused as a result of normal operations, accidents, deterioration, or severe natural events such as earthquake and storms. Sometimes the extent and location of damage can be determined through visual inspection. But visual inspection technique has a limited capability to detect the damage, especially when the damage lies inside the structure and is not visible. So an effective and reliable global damage assessment methodology is necessary for determination of damage state particularly for these inaccessible regions.

Modal parameters based damage detection method has several advantages over alternative techniques due to the fact that the modal parameters depend only on the mechanical characteristics of the structure and not on the excitation applied. Review of modal parameter based damage detection methods was carried out by Doebling et al. [1] and Fan and Qiao [2]. Since natural frequencies can be measured more easily than mode shapes and are less affected by experimental errors; it has been used as a probable damage indicator by many researchers $[3,4]$. However, its application is somewhat limited due to its low sensitivity to damage; in particular when the damage is located at regions of low stress. Further, information regarding local damage is associated with higher modes which are difficult to extract experimentally and therefore are not available for damage detection. Alternately, since mode shape represents the relative displacement of all the parts of the structures for that particular mode, they can thereby provide the spatial information about sources of vibration changes. Damage in the structure changes the mode shape locally. The commonly used method for comparing two mode shapes is the modal assurance criterion (MAC) [5] value which measures the similarity of two mode shapes. A MAC value of 1 is a perfect match and value tends to 0 means they are completely dissimilar. As the damage indicator, mode shapes provide few advantages over natural frequencies, such as, the mode shapes are less sensitive to environmental effects, like temperature [6]. A test on reinforced concrete bridge proved MAC value is a better indicator of damage than natural frequency [7]. However, the measured mode shapes are more prone to noise contamination than natural frequencies. This limits the use of mode shape as the lone damage indicator. A lot of works has been carried for a better damage indicator by combining natural frequencies, mode shapes and other mode shape derivatives. Meruane and Heylen [8] 
suggested an objective function using a combination of frequency differences and MAC values and it was found suitable damage indicator for damage detection problems.

A damage detection problem using changes in natural frequencies and/or mode shapes is basically an inverse problem, where one objective function, defined in terms of discrepancies between the vibration data identified by modal testing and those computed from analytical model, is minimized or maximized. However, these relationships are very complex involving a large number of local optima, hence making the problem too difficult to be solved by conventional optimization algorithms such as conjugate gradient method. In comparison, recent computational intelligence methods, such as artificial neural network [10-13], genetic algorithms $[8,14-17]$, and more recent cooperative optimization techniques, such as ant colony optimization technique $[9,18-$ 20] and swarm intelligence techniques [21-26], are able to map easily the cause-effect relationship between damage and modal parameters.

In the present study an extended form of ant colony optimization (ACO) [27] technique called continuous ant colony optimization $\left(\mathrm{ACO}_{\mathrm{R}}\right)$ [28], which is capable of solving continuous optimization problem, is used for damage detection problems. ACO algorithms are inspired by the behavior of ant colonies, which are almost blind, still capable of finding the shortest route from their nests to feeding sources and back. This behavior is due to ants' capacity for transmitting information between themselves, through pheromone trail along the chosen path. Due to its capability for searching a better solution to computationally hard optimization problems, $\mathrm{ACO}_{\mathrm{R}}$ has found its application in solving many complex engineering optimization problems such as, optimization of water resource [29], active vibration control [30], optimizing laminated composites [31], damage detection problems [9], history matching and uncertainty quantification for predicting performance of reservoir [32], supply chain inventory problems [33], and optimal portfolio selection problems [34]. The present study applies $\mathrm{ACO}_{\mathrm{R}}$ algorithm for damage assessment problems. A suitable objective function is formulated for this study which is then solved using $\mathrm{ACO}_{\mathrm{R}}$ to estimate the damaged member. The damage is modeled as reduction in stiffness using a factor "stiffness reduction factor" and keeping mass unchanged. The parameters of $\mathrm{ACO}_{\mathrm{R}}$ algorithms are controlled properly to achieve the optimal results economically in terms of computational cost, which is then validated with a published result. Further a laboratory tested data for a beam is used to validate the accuracy of proposed technique. Finally, some numerical experimentation is carried out to demonstrate the efficiency of this method for wide range of practical problems such as beam and plane frame as well as space frames.

\section{Theoretical Background}

2.1. Continuous Ant Colony Optimization. Ant colony optimization [27, 28] algorithms are inspired by the foraging behavior of ant, at the core of which is the indirect communication between the ants by means of chemical pheromone trails which enables them in finding the shortest paths from their nests to feeding sources and back. This iterative approach of solving discrete as well as continuous optimization problems usually consists of two basic steps such as, constructing candidate solutions in a probabilistic way by using a probability distribution over the search space and modifying the probability distribution, using the candidate solutions in a way that is deemed to bias future sampling toward high quality solutions.

In case $\mathrm{ACO}$ applied to combinational optimization problems, the set of available solution components are defined by the problem formulation and the ant samples a component to be added to the current solution set based upon the discrete probability distribution function associated with each element of the set. In $\mathrm{ACO}_{\mathrm{R}}$ this idea has been shifted to use a continuous probability density function (PDF) instead of discrete probability distribution one. One of the most popular functions to be used as a PDF is the Gaussian function, where a Gaussian kernel $G^{i}(x)$ is defined as a weighted sum of several one-dimensional Gaussian functions $g_{l}^{i}(x)$ as below:

$$
G^{i}(x)=\sum_{l=1}^{k} \omega_{l} g_{l}^{i}(x)=\sum_{l=1}^{k} \omega_{l} \frac{1}{\sigma_{l}^{i} \sqrt{2 \pi}} e^{\left(x-\mu_{l}^{i}\right)^{2} / 2\left(\sigma_{l}^{i}\right)^{2}},
$$

where $i=1,2, \ldots, n$ is the number of dimensions of the problem, which identifies a single such PDF. The Gaussian kernel $G^{i}(x)$ is parameterized with three vectors of parameters: $\omega$ is the vector of weights associated with the individual Gaussian functions, $\mu^{i}$ is the vector of means, and $\sigma^{i}$ is the vector of standard deviations. The cardinality of all these vectors is equal to the number of Gaussian functions constituting the Gaussian kernel. For convenience, we will use the parameter $k$ to describe it, hence:

$$
|\omega|=\left|\mu^{i}\right|=\left|\sigma^{i}\right|=k .
$$

The algorithm is started with random solution set of cardinality $k$, which corresponds to the pheromone value initialization in ACO algorithms for discrete optimization problems. At each iteration steps better set of generated solutions is added to the population and the same number of the worst solutions is removed from it. This action biases the search process towards the best solutions and hence it is equivalent the pheromone update in discrete ACO.

Mathematically, for constructing a solution, an ant chooses at each construction step $i=1, \ldots, n$, a value for decision variable $X_{i}$. For performing this choice, an ant uses the Gaussian kernel $G^{i}(x)$ defined for $i$ th dimension. As direct sampling of Gaussian kernel $G^{i}$ is problematic, an alternate approach is followed in $\mathrm{ACO}_{\mathrm{R}}$ as follows.

Exactly one of the Gaussian functions $j$ is chosen probabilistically using (3), which is then used for all $n$ construction steps.

$$
P_{j}=\frac{\omega_{j}}{\sum_{l=1}^{k} \omega_{l}}, \quad \forall j=1, \ldots, k,
$$

where $\omega_{j}$ is the weight of Gaussian function $j$, which is obtained as follows. All solutions in the population are ranked 
according to their quality (e.g., the inverse of the objective function value in the case of minimization) with the best solution having rank 1 . Assuming the rank of the $j$ th solution in the population to be $r$, the weight $\omega_{j}$ of the $j$ th Gaussian function is calculated according to the following formula:

$$
\omega_{j}=\frac{1}{q k \sqrt{2 \pi}} e^{-(r-1)^{2} / 2 q^{2} k^{2}} .
$$

This essentially defines the weight to be a value of the Gaussian function with argument $r$, with a mean of 1.0, and a standard deviation of $q k$. The term $q$ is a parameter of the algorithm. In case the value of $q$ is small, the best-ranked solutions are strongly preferred, and in case it is larger, the probability becomes more uniform. Due to using the ranks instead of the actual fitness function values, the algorithm is not sensitive to the scaling of the fitness function.

For each selected Gaussian function, the values of the $i$ th variable of all the solutions $\left\{s_{1}^{i}, \ldots, s_{k}^{i}\right\}$ in the archive becomes the elements of the vector $\mu^{i}$,

$$
\mu^{i}=\left\{\mu_{1}^{i}, \ldots, \mu_{k}^{i}\right\}=\left\{s_{1}^{i}, \ldots, s_{k}^{i}\right\} .
$$

Further the values of the standard deviation $\sigma_{l}^{i}$ at construction step $i$ can be calculated from the average distance from the chosen solution $s_{l}$ to other solutions in the archive and then by multiplying it by the parameter $\xi$,

$$
\sigma_{l}^{i}=\xi \sum_{e=1}^{k} \frac{\left|s_{e}^{i}-s_{l}^{i}\right|}{k-1} .
$$

The parameter $\xi(>0)$, which is the same for all the dimensions, has an effect similar to that of the pheromone evaporation rate in $\mathrm{ACO}$. The higher the value of $\xi$, the lower the convergence speed of the algorithm. As mentioned before, this whole process is repeated for each dimension $i=1, \ldots, n$ and each time the average distance $\sigma_{l}^{i}$ is calculated only with the use of the single dimension $i$. This ensures that the algorithm is able to adapt to linear transformations of the considered problem.

2.2. Parameters of $A C \mathrm{O}_{R}$ Algorithm. One of the disadvantages associated with ACO algorithm is that it may converge into some local optimum thereby leading to wrong results. Again, it may require great amount of computation time for getting the results. To minimize the convergence time and to increase the accuracy there have been a number of works on algorithm refinements and hybridization [35-38]. However, the performance of $\mathrm{ACO}_{\mathrm{R}}$ algorithm greatly depends on the parameters of the algorithm, that is, $k, q$, and $\xi$. Hence with proper selection of these parameters the performance of algorithm can be improved by a great extent.

These parameters for $\mathrm{ACO}_{\mathrm{R}}$ algorithm are not independent of each other rather they depend on the dimensions of the problem. When the solution archive size $(k)$ is very small, a few found solutions are stored in the solution archive and consequently the experience of other ants cannot be utilized in a proper way to generate better solutions. On the other hand more solution archive size increases simulation time and decreases the quality of found solutions, since a big solution archive keeps a larger amount of solutions with less quality [39]. Based on numerical experimentation it was found that a better solution is achieved by considering archive size between 1.5-2.5 times of the problem dimension. Further, it is better to use more number of ants for implementation of parallel computing with this algorithm. Though this may increase the number of function evaluations but the actual time required by the algorithm will be significantly less by virtue of parallel computing. For the present study 10 solutions are added to solution archive per iteration and equal numbers of worst solutions are deleted from the solution archive. In order to avoid assignment of weights close to zero, to the last $r$ solutions of the sorted ants, Movahedipour [35] defined a limit $\mathrm{C}$ and find corresponding $q$ value as

$$
r=1+q K \sqrt{-2 \ln (C)+\ln (q K)+0.9189} \text {. }
$$

It may probable that the ants may converge to a local optima or it may true for some run that the number of iteration is not enough for convergence thus not achieving target accuracy. Hence, to ensure proper convergence, each problem is run multiple times and the run yielding lowest objective function value is considered as actual damage scenario.

2.3. Damage Detection Procedure. For a properly modeled structure, the eigenvalue equation is given by

$$
\left([K]-\omega_{i}^{2}[M]\right)\left\{\phi_{i}\right\}=0, \quad i=1, \ldots, n,
$$

where $[K]$ and $[M]$ are the global stiffness and mass matrices respectively, and $\omega_{i}$ and $\phi_{i}$ represent the natural frequency and corresponding vibration mode shape. It can be assumed that introduction of damage to a structure will result in reduction of local stiffness of the structure whereas the change in mass may be neglected. Hence we can rewrite (8) for a damaged system as

$$
\left(\left[K_{d}\right]-\left(\omega_{i}^{d}\right)^{2}[M]\right)\left\{\phi_{i}^{d}\right\}=0, \quad i=1, \ldots, n,
$$

where $\left[K_{d}\right]$ and $\left[M_{d}\right]$ are the global stiffness and mass matrices respectively, and $\omega_{i}^{d}$ and $\phi_{i}^{d}$ represents the natural frequency and corresponding vibration mode shape for damaged structure respectively. It has been seen that for low frequency measurements we can model damage as the reduction in stiffness as a scalar variable between $[0,1)$, where zero value corresponds to no damage case and a value near to one corresponds to rupture condition [40]. Mathematically we can define this as

$$
\begin{gathered}
{\left[K_{d}\right]=\sum_{i}\left(1-\beta_{i}\right)\left[K_{i}\right],} \\
\beta_{i}=\frac{E I_{u}^{i}-E I_{d}^{i}}{E I_{u}^{i}},
\end{gathered}
$$

where $E$ is defined as Young's modulus of elasticity and $I$ is the moment of inertia and the subscript $u$ and $d$ denotes 
the undamaged and damaged states, respectively, and $\beta$ is the stiffness reduction factor which is defined as the ratio of reduction in stiffness of the element at the damaged state to the stiffness at the undamaged state. Equation (9) forms the basis of the damage detection method through an inverse procedure. The natural frequencies and the mode shapes are measured for the damaged structure. Then $\mathrm{ACO}_{\mathrm{R}}$ algorithm is used to search a particular pair of stiffness reduction factor for which the numerical natural frequencies and corresponding mode shapes exactly match with that of the measured natural frequencies and mode shapes. The numerical model of undamaged structure is generally considered as the initial model for the optimization. The SRF values for which the exact match between the measured and calculated natural frequencies and mode shapes are observed represents the actual damage location and amount. The usual approach to solve the inverse problem of damage detection involves minimization of an objective function, which is defined in terms of discrepancies between the vibration data identified by modal testing and those computed from the analytical model. Meruane and Heylen [8] suggested that an objective function using a combination of frequency differences and MAC values are the suitable damage indicator for damage detection problems. Accordingly, the objective function used for this study is given by;

$$
F=\sqrt{\frac{1}{n} \sum_{i=1}^{n}\left(\left(\frac{f_{i}^{m}}{f_{i}^{c}}\right)-1\right)^{2}}+\sum_{i=1}^{n}\left(1-\mathrm{MAC}_{i i}\right),
$$

where $f_{i}^{m}$ represents the measured frequency or the frequency obtained from finite element simulation in absent of measured frequency and $f_{i}^{c}$ represents the frequencies obtained in optimization iteration steps. $n$ is the number of input response parameters (natural frequencies or mode shapes) and for this study is taken as six. The MAC value represents the correlation between two mode shapes and is defined as

$$
\operatorname{MAC}_{i}=\frac{\left(\phi_{u, i}^{T} \phi_{d, i}^{T}\right)^{2}}{\left(\phi_{u, i}^{T} \phi_{u, i}\right)\left(\phi_{d, i}^{T} \phi_{d, i}\right)},
$$

where $\phi_{i}$ gives the $i$ th mode shape.

In practice for damage identification the natural frequencies and mode shapes are identified from modal testing, and it is assumed that the finite element model representing the structure will provide the same modal values as those identified from modal testing. However, it does not happen due to several errors associated with inaccurate modeling, erroneous measurement and environmental noises, and so forth. If these noises are greater than the actual changes of modal parameters due to structural damage, then the information of real structural damage cannot be accurately identified. One method to minimize these discrepancies is model updating. The basic assumption behind model updating is that for a linear and undamped system, the errors in modeling of boundary conditions and joints can be eliminated by adjusting the material properties of the elements [41]. For the present inverse problem the model updating and identification of undamaged structure is first carried out in order to minimize the variation of structural parameters and then this identified undamaged model is used as the initial model for damage detection.

2.4. Noise Modeling. Due to associated uncertainties in test results, there is always a discrepancy between modal predictions by mathematical model and test results. For the numerical simulation study, the simulated noisy natural frequencies and mode shapes are obtained by adding a random value as given by

$$
\begin{aligned}
& f_{\text {noisy }}=f_{\text {analytical }}\left(1+\frac{\eta \alpha}{100}\right), \\
& \phi_{\text {noisy }}=\phi_{\text {analytical }}\left(1+\frac{\eta \alpha}{100}\right),
\end{aligned}
$$

where $\eta$ is a random number in the interval $[-1,1]$ and $\alpha$ is the damage level parameter. It is common to consider the noise associated with measurement of natural frequency is $1 \%$ and that of mode shape is $10 \%$ [42]. Hence, in order to simulate the experimental natural frequencies in a realistic way, $1 \%$ random noise is added to the numerical natural frequency and $10 \%$ random noise is added to the numerical mode shape.

\section{Results and Discussions}

Computer codes are developed based on formulations outlined in previous sections and applied to beam and frame type structural systems. The structures are modeled with EulerBernoulli beam element and damage is represented in terms of SRF. The modal parameters are calculated numerically from eigenvalue analysis. The result and discussion portion is broadly divided into three parts. First part deals with damage detection in beam type structures. In this part the natural frequency from experiment is used for damage detection in a beam, which is then extended to include a numerically simulated beam for detecting single and multiple damages using noisy frequency along with mode shape data. The second part deals with damage detection in frame type structures. A 2-storey rigid frame structure as considered by $\mathrm{Yu}$ and $\mathrm{Xu}$ [9] is considered for demonstration of improvements in computational cost, efficiency, and robustness that could be achieved by proper selection of $\mathrm{ACO}_{\mathrm{R}}$ parameters. This further extended for damage detection in a 3-bay, 4-storey plane frame structure. In the last part, the damage in a 5storey space frame structure is detected by the proposed algorithm.

\subsection{Damage Assessment in Beam Type Structure}

3.1.1. Experimental Validation. Modal testing is carried out to capture vibration properties of a steel cantilever beam of dimensions $530 \mathrm{~mm} \times 24 \mathrm{~mm} \times 6 \mathrm{~mm}$ in order to demonstrate the applicability of developed algorithm in damage detection of a real structure. These experiments are carried out in the Structural Engineering and Material Testing Laboratory of Indian Institute of Technology, Kharagur. Figure 1 presents the setup for conducting this 
TABLE 1: Natural frequency of the structure (in $\mathrm{Hz}$ ).

\begin{tabular}{lccccc}
\hline Mode & & Undamaged structure & Single damage case & Double damage case \\
& Experimental & Analytical & Updated & 16.25 & 16.24 \\
1st & 16.41 & 17.4722 & 16.5412 & 103.99 & 103.32 \\
2nd & 103.63 & 109.4966 & 103.6623 & 289.52 & 288.60 \\
3rd & 290.00 & 306.5980 & 290.2616 & 564.38 & 563.76 \\
4th & 567.76 & 600.8375 & 568.8231 & 932.63 & 924.87 \\
5th & 938.31 & 993.3336 & 940.4060 & & \\
\hline
\end{tabular}

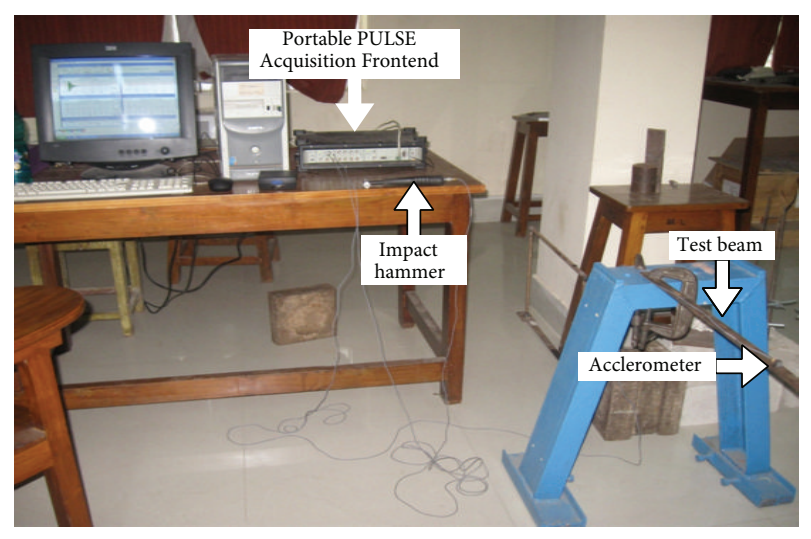

FIGURE 1: Experimental setup.

experiment. The natural frequencies are estimated experimentally by modal testing through 3560C B \& K Portable PULSE Acquisition Frontend. A hammer of B \& K 8206$002,2.3 \mathrm{mV} / \mathrm{N}$ is used to excite the structure. A 4507 Deltra Tron accelerometer of $10 \mathrm{mV} / \mathrm{ms}^{2}$, max $700 \mathrm{~ms}^{2}$ (Frequency range-Amplitude $( \pm 10 \%) 0.3 \mathrm{~Hz}$ to $6 \mathrm{kHz}$ and Pulse $\left( \pm 5^{\circ}\right)$ $2 \mathrm{~Hz}$ to $5 \mathrm{kHz}$ ) is used to capture acceleration data which then are analyzed by a signal analyzer 3560C B \& K Portable PULSE data Acquisition Frontend. The Frontend generated FRF spectrum data are then analyzed in ME Scope (Ver. 5.0) software to get the modal parameters.

Initially, the undamaged beam is tested and its response is recorded. Then single damage of depth $2 \mathrm{~mm}$ and width $1.8 \mathrm{~mm}$ is introduced at $100 \mathrm{~mm}$ distance from fixed support by making a fine saw cuts perpendicular to the longitudinal axis. Further another cut of same amount is done at a distance of $200 \mathrm{~mm}$ from the support in addition to previous cut. This represents double damage case. The response is calculated after each cut respectively. Young's modulus and mass density of the beam is considered as $200 \times 10^{9} \mathrm{~N} / \mathrm{m}^{2}$ and $7800 \mathrm{~kg} / \mathrm{m}^{3}$, respectively. Figure 2 represents the schematic diagram of the test beam structure and Figure 3 shows the two damage case of the test beam.

For numerical simulation, the experimental beam divided into 20 equal Euler-Bernoulli beam elements. ABAQUS FEA software is used to numerically estimate the stiffness reduction factor for cracked beam element. 4-noded shell elements (S4R) available in ABAQUS are used to analyze the beam and crack is simulated by removing the elements at the cracked location. A static load of $100 \mathrm{~N}$ is applied at the free end of this model and the resulting deflection is calculated. In next step, second beam model is selected with similar element and with similar loading conditions. Young's modulus for the elements near the cracked location (i.e., those falls within element 4 and element 8 of the Figure 2) is reduced to such an extent so that resulting deflection will match to the first model. The reduction in stiffness for this condition gives the amount of damage present in corresponding elements.

The first five natural frequencies are measured and used for the present study. Table 1 presents a comparison between measured and numerical natural frequencies. The model updating is carried out to minimize the discrepancy between experimental as well as numerical results. Young's modulus and density of the beam material are considered as the variables for updating process. From the tabular results, it is clear that after updating the model the natural frequencies calculated from the finite element model is very close to the experimental values. This updated model is used for the further study and damage detection. A comparison is made for damage detection using first three and first five sets of frequencies.

Various parameters required for $\mathrm{ACO}_{\mathrm{R}}$ algorithm are considered as follows. The size of solution archive is taken as 40. The value of $r$ and $C$ are fixed as 5 and 0.001, respectively. The corresponding value of $q$ is calculated as 0.038 . The value of pheromone evaporation rate $\xi$ is taken as 0.85 . Number of ants taken is 10. Three experiments are conducted for each case and the experiment providing minimum objective function is considered as the final damage scenario. The maximum iteration per experiment is fixed at 1000. The damage detection results are shown in graphical form as seen in Figure 4.

It is seen from Figure 4 that first three natural frequencies are sufficient to detect damage for single damage case. However, for double damage case, few false locations are detected when first three frequencies are used. These false detections are reduced to a great extent if first five natural frequencies are considered. Thus, one can conclude that first five frequencies can be used for locating and quantifying damages with reasonable accuracy.

3.1.2. Assessment of Multiple Damages in Beam. Numerical simulations are carried out to demonstrate the effectiveness of the proposed damage assessment algorithm. A steel cantilever beam as described in previous section is taken 


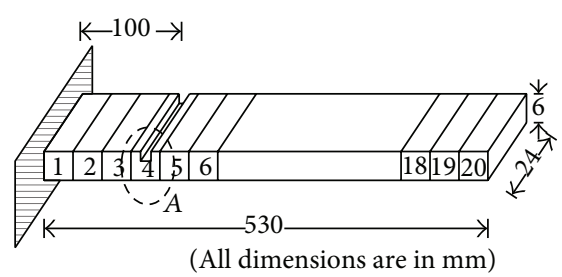

(a) Single damage case

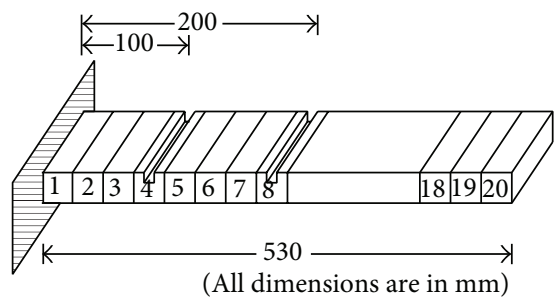

(b) Double damage case

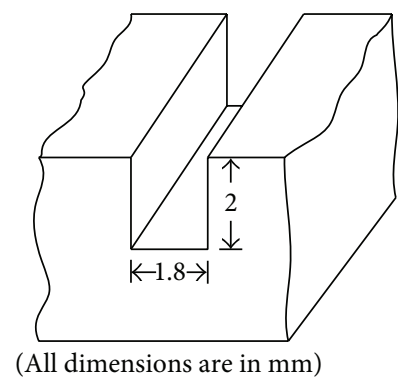

(c) Damage detail at " $A$ "

Figure 2: Experimental beam model (not to scale).

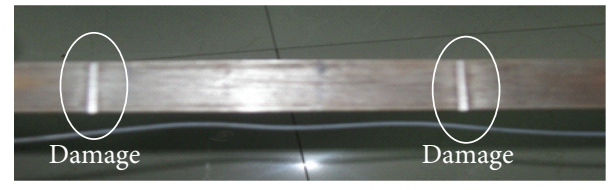

FIGURE 3: Damages in experimental beam.

in this study. Single and multiple damaged conditions are simulated for the purpose. In total, three random cases, as shown in Table 2, are considered for the present study. First six natural frequencies and corresponding mode shapes as calculated from finite element simulation are considered in the study.

The algorithm is evaluated for its performance when both natural frequency and mode shape (in the form of MAC value) is used as damage indicator. Noise is added up to $1 \%$ to the theoretically calculated natural frequencies and up to $10 \%$ noise in theoretically calculated mode shape values. The parameters of $\mathrm{ACO}_{\mathrm{R}}$ algorithm is kept similar to previous section. Like the previous section, three experiments are conducted considering different initial seeds for each case and the experiment providing minimum objective function is considered as the final damage scenario. The maximum iteration per experiment is fixed at 1000. The results are shown in Figure 5. Also, the statistical results for the experimentations are shown in Table 3 for these runs. Further, it is quite probable that the stiffness/mass matrices considered for the numerical study may be different than the real structure. Considering this aspect a comparison is made to check the validity of the developed algorithm in damage detection of structures having some variation in stiffness/mass matrix. The algorithm is run for five times with different stiffness/mass ratio and the statistical results are produced in Table 4.

From Figures 5(a) to 5(c) it is seen that the proposed methodology can provide a good estimation of damage location and its quantification for all cases. For the case of noise free vibration data, the algorithm is able to provide exact damage scenario without any false detection. However, for multiple damage cases with noisy vibration data, the algorithm can detect the actual damage locations
TABLE 2: Various damage cases.

\begin{tabular}{ll}
\hline Case & Description \\
\hline E1 & 10\% damage at element 5 \\
E2 & E1 $+15 \%$ damage at element 9 \\
E3 & $\begin{array}{l}\text { E2 }+10 \% \text { damage at element } 11+20 \% \text { damage at } \\
\text { element } 15\end{array}$ \\
\hline
\end{tabular}

and corresponding damage amount with quite impressive accuracy. It is interesting to note that few false damages with negligible quantity are observed towards free end of cantilever while noisy data are considered. This happens as the free ends of a cantilever are regions of low stress, and, hence, large amount of damage will affect the vibration characteristics least. It is also true that a little error in vibration data may result a false damage at free end. However, the proposed algorithm has the efficacy in detecting all true damage locations with sound accuracy. Furthermore, it is observed from the tabulated results that the standard deviation values for all these runs are significantly less in comparison to actual damages. This indicates that the algorithm has good resistance to initial starting position. Furthermore, from Table 4 it is observed that the algorithm could able to produce satisfactory damage identification results for all considered cases. The algorithm is not only able to detect all damaged elements but also able to quantify it with significant precision which indicates the ability of the algorithm to detect and quantify damages in structures for which precise numerical model is not available.

\subsection{Damage Detection of a Plane Frame Structure}

3.2.1. Validation of the Algorithm. A 2-storey rigid frame structure as presented by $\mathrm{Yu}$ and $\mathrm{Xu}$ [9] is considered for validation of proposed algorithm. Figure 6 shows the finite element model of the frame and corresponding dimensions. The numbers in the circle indicate the element number and the others near to the frame indicate the node number. Area of cross section of column and beam is considered as $0.00298 \mathrm{~m}^{2}$ and $0.0032 \mathrm{~m}^{2}$, respectively. The moment of inertia for column and beam is $1.26 \times 10^{-5} \mathrm{~m}^{4}$ and $2.36 \times$ $10^{-5} \mathrm{~m}^{4}$, respectively. The mass densities of column and beam 


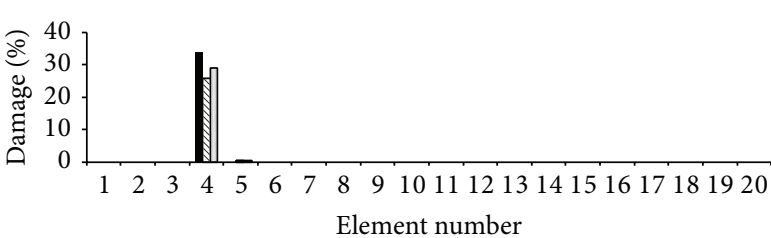

Actual damage

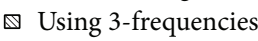

$\square$ Using 5-frequencies

(a) Results of damage detection for single damage

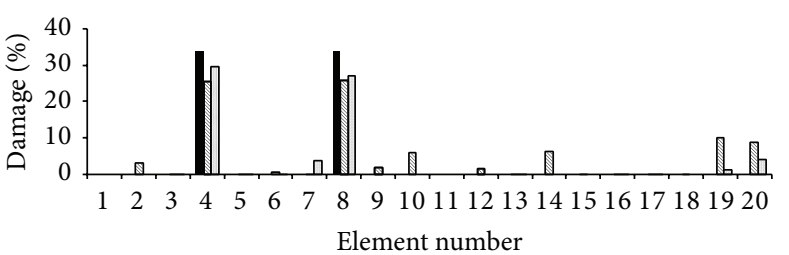

Actual damage

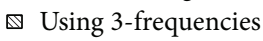

$\square$ Using 5-frequencies

(b) Results of damage detection for double damage

Figure 4: Damage detection results for the experimental beam.

TABLE 3: Statistical results for damage identification in cantilever beam.

\begin{tabular}{|c|c|c|c|c|c|c|c|c|}
\hline \multirow{3}{*}{ Damage case } & \multicolumn{8}{|c|}{ Detected damage amounts } \\
\hline & \multicolumn{2}{|c|}{ 10\%@5 } & \multicolumn{2}{|c|}{ 15\%@ 9} & \multicolumn{2}{|c|}{ 10\%@11 } & \multicolumn{2}{|c|}{ 20\%@15 } \\
\hline & Mean & Std. Dev. & Mean & Std. Dev. & Mean & Std. Dev. & Mean & Std. Dev. \\
\hline \multicolumn{9}{|c|}{ Noise free data } \\
\hline Single element & 10.00 & $5.5 e-6$ & & & & & & \\
\hline Two-element & 10.00 & $1.1 e-5$ & 15.00 & 0.000 & & & & \\
\hline Four-element & 10.00 & $1.1 e-5$ & 15.00 & $4.5 e-5$ & 10.00 & $2.3 e-5$ & 20.00 & 0.00 \\
\hline \multicolumn{9}{|c|}{$0.5 \%$ noise in natural frequency and $5.0 \%$ noise in mode shape data } \\
\hline Single element & 9.14 & $5.5 e-5$ & & & & & & \\
\hline Two-element & 9.73 & $7.3 e-4$ & 15.20 & $2.9 e-4$ & & & & \\
\hline Four-element & 8.46 & $1.9 e-4$ & 14.41 & $2.3 e-4$ & 9.40 & $4.1 e-5$ & 19.47 & $6.7 e-4$ \\
\hline \multicolumn{9}{|c|}{$1.0 \%$ noise in natural frequency and $10.0 \%$ noise in mode shape data } \\
\hline Single element & 11.10 & $4.9 e-5$ & & & & & & \\
\hline Two-element & 11.87 & $4.5 e-5$ & 14.07 & $1.3 e-4$ & & & & \\
\hline Four-element & 13.66 & 0.00 & 13.81 & $1.1 e-4$ & 10.30 & $8.1 e-5$ & 20.43 & $5.5 e-6$ \\
\hline
\end{tabular}

TABLE 4: Damage detection results considering variation in stiffness/mass matrix.

\begin{tabular}{|c|c|c|c|c|c|c|c|c|}
\hline \multirow{3}{*}{ Damage case } & \multicolumn{8}{|c|}{ Detected damage amounts } \\
\hline & \multicolumn{2}{|c|}{ 10\%@ 5} & \multicolumn{2}{|c|}{ 15\%@9 } & \multicolumn{2}{|c|}{ 10\%@11 } & \multicolumn{2}{|c|}{ 20\%@15 } \\
\hline & Mean & Std. Dev. & Mean & Std. Dev. & Mean & Std. Dev. & Mean & Std. Dev. \\
\hline \multicolumn{9}{|c|}{$0.5 \%$ variation in stiffness/mass matrix } \\
\hline Single element & 8.34 & $5.80 e-1$ & & & & & & \\
\hline Two-element & 9.23 & $5.60 e-1$ & 14.31 & $5.00 e-1$ & & & & \\
\hline Four-element & 9.38 & $4.60 e-1$ & 14.48 & $3.90 e-1$ & 9.49 & $3.80 e-1$ & 19.76 & $1.80 e-1$ \\
\hline \multicolumn{9}{|c|}{$1.0 \%$ variation in stiffness/mass matrix } \\
\hline Single element & 7.71 & 1.90 & & & & & & \\
\hline Two-element & 7.91 & $3.60 e-1$ & 13.15 & $3.2 e-1$ & & & & \\
\hline Four-element & 8.57 & 1.10 & 13.79 & $9.00 e-1$ & 8.82 & $8.80 e-1$ & 19.45 & $4.10 e-1$ \\
\hline
\end{tabular}

materials are $8590 \mathrm{~kg} / \mathrm{m}^{3}$ and $7593 \mathrm{~kg} / \mathrm{m}^{3}$, respectively. The modulus of elasticity is considered as $2.0 \times 10^{11} \mathrm{~N} / \mathrm{m}^{2}$.

Four damage cases are considered as shown in Table 5 for the validation of the proposed computer code. The damage is simulated by reducing the stiffness of the specific element by an amount corresponding to damage percentage. For example, in $\mathrm{F} 1$ case the damage is simulated by reducing the stiffness of element 17 by an amount $0.5 \%$. First six natural frequencies and corresponding mode shapes are considered for the study. The size of solution archive is taken as 30 . The values of $r$ and $C$ are considered as 5 and 0.001 , respectively. The corresponding value of $q$ is calculated as 0.05 . The results for proposed damage detection methods are shown in Table 6.

The maximum number of iterations is kept as 1000 in all cases. However, for case F4, program is run for second 


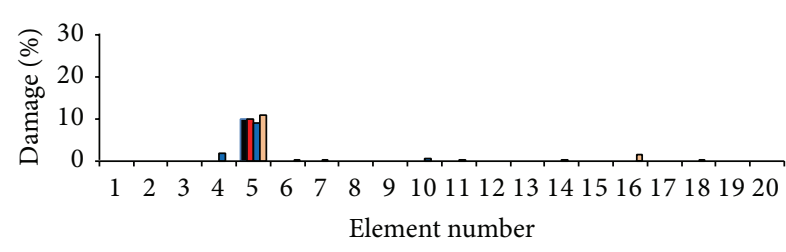

- Actual damage

$\square$ Clean data

$\square 0.5 \%$ noise in frequency and $5 \%$ noise in mode shape

$\square \quad 1.0 \%$ noise in frequency and $10 \%$ noise in mode shape

(a) Damage detection results for single element damage (E1) case

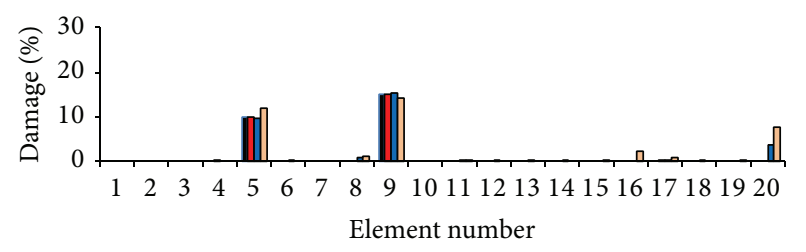

- Actual damage

$\square$ Clean data

$\square 0.5 \%$ noise in frequency and $5 \%$ noise in mode shape

$\square \quad 1.0 \%$ noise in frequency and $10 \%$ noise in mode shape

(b) Damage detection results for double element damage (E2) case

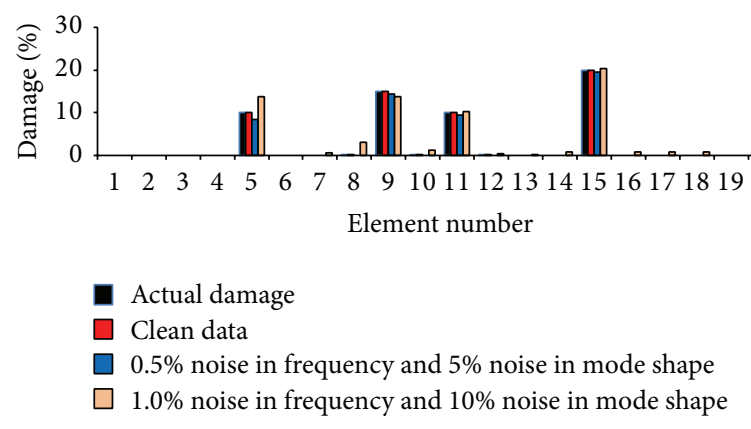

(c) Damage detection results for four-element damage (E3) case

Figure 5: Results of damage detection in numerical cantilever beam.

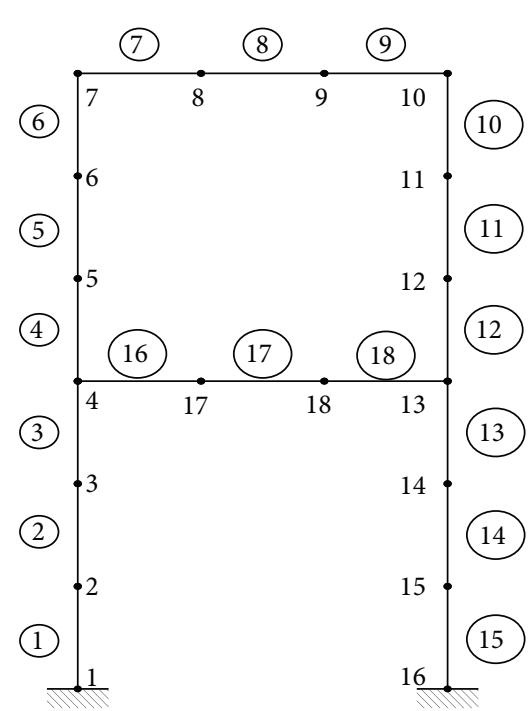

Figure 6: Two-storey plane frame as considered by $\mathrm{Yu}$ and $\mathrm{Xu}$ [9].

time with 2000 iterations in order to get an improved result. The performance of proposed algorithm is measured in terms of improvement in accuracy which is expressed as follows:

Improvement in accuracy (\%)

$$
=\frac{\left|d_{\text {actual }}-d_{\text {reference }}\right|-\left|d_{\text {actual }}-d_{\text {estimated }}\right|}{d_{\text {actual }}} \times 100 \text {. }
$$

TABLE 5: Various damage conditions of the frame.

\begin{tabular}{ll}
\hline Case & Description \\
\hline F1 & $\begin{array}{l}0.5 \% \text { at element } 17 \\
\text { F2 }\end{array}$ \\
F3 & $\begin{array}{l}\text { 10\% damage at element } 8 \text { and element } 17, \text { respectively } \\
\text { element } 17,20 \% \text {, respectively }\end{array}$ \\
F4 & $\begin{array}{l}15 \% \text { at element } 11, \text { and } 3 \% \text { at } \\
\text { element } 17, \text { respectively }\end{array}$ \\
\hline
\end{tabular}

Here the terms $d_{\text {actual }}, d_{\text {reference }}$, and $d_{\text {estimated }}$ are representing simulated damage percentage, damage percentages as estimated in by $\mathrm{Yu}$ and $\mathrm{Xu}$ [9] and damage percentage as estimated in current study, respectively. The negative value of improvement in accuracy represents the degradation of accuracy than the reference literature.

It is seen from Table 6 that, for all but F4 case, after 1000 iterations we are able to achieve better results than $\mathrm{Yu}$ and $\mathrm{Xu}$ [9] by utilizing suitable ant algorithm parameters. However, in F4 case after 2000 iterations, we could achieve much better results than $\mathrm{Yu}$ and $\mathrm{Xu}$ [9]. It is worth to note that $\mathrm{Yu}$ and $\mathrm{Xu}$ [43] could achieve the above mentioned results after 10000 iterations.

3.2.2. Damage Detection of a 3-Bay and 4-Storey Structure. Further, to demonstrate the effectiveness of this method a 4-storey, 3-bay steel space frame as shown in Figure 7 is 
TABLE 6: Comparison of damage scenario between the present algorithm and [9].

\begin{tabular}{|c|c|c|c|c|c|c|c|c|c|c|c|}
\hline \multirow{2}{*}{ Damage case } & \multirow{2}{*}{ Element } & \multirow{3}{*}{ Actual damage } & \multicolumn{6}{|c|}{ Detected damage } & & & \\
\hline & & & \multicolumn{3}{|c|}{ As per $\mathrm{Yu}$ and $\mathrm{Xu}[9]$} & \multicolumn{3}{|c|}{ Proposed algorithm } & \multicolumn{3}{|c|}{ Improvement in accuracy (\%) } \\
\hline \multicolumn{2}{|c|}{ Percentage of noise included* } & & 0 & 5 & 10 & 0 & 5 & 10 & 0 & 5 & 10 \\
\hline $\mathrm{F} 1$ & 17 & 0.5 & 0.42 & 0.42 & 0.40 & 0.5 & 0.5 & 0.4 & 16.0 & 16.0 & 0.0 \\
\hline \multirow{2}{*}{$\mathrm{F} 2$} & 8 & 20 & 18.8 & 17.5 & 16.5 & 20.0 & 20.8 & 19.6 & 6.0 & 8.5 & 15.5 \\
\hline & 17 & 20 & 18.5 & 17.2 & 16 & 20.0 & 20.0 & 14.7 & 7.5 & 14.0 & -6.5 \\
\hline \multirow{3}{*}{ F3 } & 8 & 10 & 11.8 & 10.8 & 14.5 & 10.0 & 10.2 & 16.8 & 18.0 & 6.0 & -23.0 \\
\hline & 11 & 20 & 17.2 & 18.5 & 14.3 & 20.0 & 20.0 & 20.9 & 14.0 & 7.5 & 24.0 \\
\hline & 17 & 3 & 4.7 & 3.5 & 5.5 & 3.0 & 3.6 & 1.2 & 56.7 & -3.3 & 23.3 \\
\hline \multirow{4}{*}{$\mathrm{F} 4^{1}$} & 5 & 15 & 13.2 & 14.5 & 14.7 & 14.9 & 13.4 & 14.4 & 11.3 & -7.3 & -2.0 \\
\hline & 8 & 15 & 12.1 & 12.6 & 13.2 & 12.0 & 11.1 & 10.4 & -0.7 & -10.0 & -18.7 \\
\hline & 11 & 20 & 18.2 & 17.9 & 15.5 & 19.8 & 19.3 & 18.0 & 8.0 & 7.0 & 12.5 \\
\hline & 17 & 3 & 4.1 & 4.4 & 4.7 & 2.7 & 2.7 & 0.0 & 26.7 & 36.7 & -43.3 \\
\hline \multirow{4}{*}{$\mathrm{F} 4^{2}$} & 5 & 15 & 13.2 & 14.5 & 14.7 & 15.0 & 15.5 & 13.8 & 12.0 & 0.2 & -6.1 \\
\hline & 8 & 15 & 12.1 & 12.6 & 13.2 & 15.0 & 14.3 & 15.0 & 19.3 & 11.1 & 11.9 \\
\hline & 11 & 20 & 18.2 & 17.9 & 15.5 & 20.0 & 20.3 & 18.6 & 9.0 & 9.1 & 15.5 \\
\hline & 17 & 3 & 4.1 & 4.4 & 4.7 & 3.0 & 1.6 & 1.9 & 36.7 & 1.0 & 19.0 \\
\hline
\end{tabular}

*Values indicate the added noise level in mode shapes. The noise level in natural frequency is taken as one tenth of that of mode shapes.

${ }^{1}$ Maximum number of iterations considered as 1000 .

${ }^{2}$ Maximum number of iterations considered as 2000 .

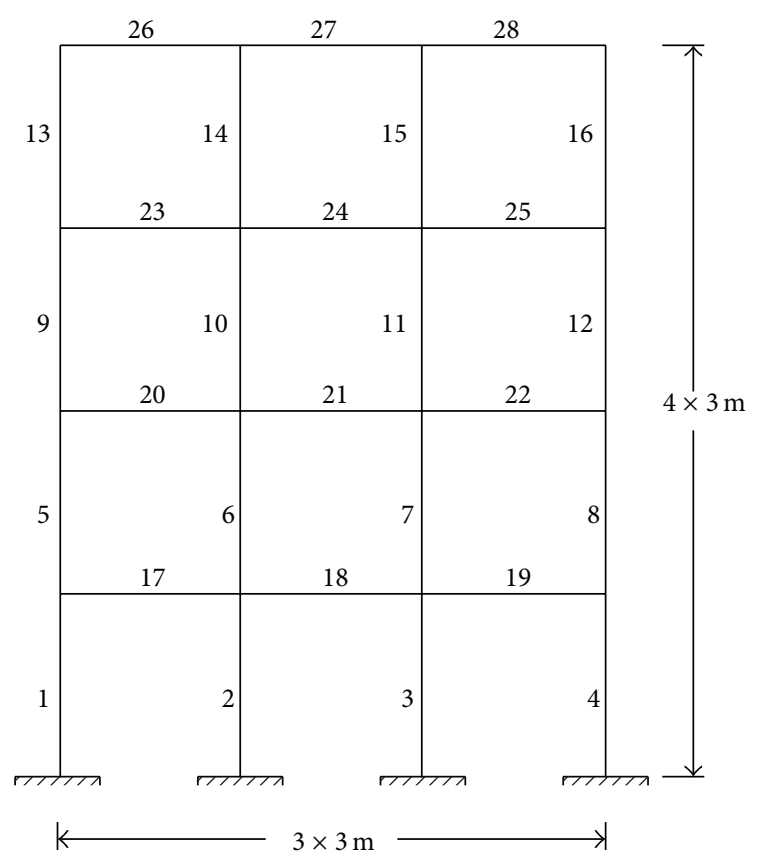

Figure 7: 3-Bay, 4-storey frame model.

considered. The cross sections for beam as well as column are considered as $20.0 \times 20.0 \mathrm{~mm}^{2}$. Young's modulus and mass density of the beam considered as $200 \times 10^{9} \mathrm{~N} / \mathrm{m}^{2}$ and $7800 \mathrm{~kg} / \mathrm{m}^{3}$ respectively. Modal analysis is conducted using finite element method to generate natural frequency and mode shape. Three random damage cases as shown in Table 7 are considered for the purpose of demonstration.
TABLE 7: Damage conditions to study damage detection in plane frame.

\begin{tabular}{ll}
\hline Case & Description \\
\hline G1 & $\begin{array}{l}\text { 10\% damage at element } 1 \\
\text { 15\% damage at element } 1 \text { and } 10 \% \text { damage at } \\
\text { G2 }\end{array}$ \\
G3 & $\begin{array}{l}\text { G2 }+15 \% \text { damage at element } 5 \text { and } 20 \% \text { damage at } \\
\text { element } 21\end{array}$ \\
\hline
\end{tabular}

TABLE 8: First six natural frequencies of undamaged frame.

\begin{tabular}{lcccccc}
\hline Mode & 1st & 2nd & 3rd & 4th & 5th & 6th \\
\hline Frequency $(\mathrm{Hz})$ & 27.86 & 75.34 & 84.76 & 133.49 & 174.00 & 180.66
\end{tabular}

First six natural frequencies (Table 8) and corresponding mode shapes are used for this study. The parameters of ACO algorithm are kept similar to beam problem. Similar to all previous studies, three experiments are conducted per each case with different random initial seeds and the experiment providing minimum objective function is considered as the final damage scenario. The maximum iteration per experiment is fixed at 1000. The obtained results for proposed damage detection methods are shown in Figures 8(a) to 8(c) and Table 9.

From the graphical results, it is clear that the proposed methodology can detect and quantify the damaged member with quite impressive accuracy in all cases. Though in fourelement damage detection case it has detected a false damage location at element 2, but it may not be harmful as it has 
TABLE 9: Statistical results for damage detection in 3-bay and 4-storey frame structure.

\begin{tabular}{|c|c|c|c|c|c|c|c|c|}
\hline \multirow{3}{*}{ Damage case } & \multicolumn{8}{|c|}{ Detected damage amounts } \\
\hline & \multicolumn{2}{|c|}{ 15\%@1 } & \multicolumn{2}{|c|}{ 10\%@2 } & \multicolumn{2}{|c|}{ 15\%@ 5} & \multicolumn{2}{|c|}{ 20\%@ @21 } \\
\hline & Mean & Std. Dev. & Mean & Std. Dev. & Mean & Std. Dev. & Mean & Std. Dev. \\
\hline \multicolumn{9}{|c|}{ Noise free data } \\
\hline Single element & 15.00 & $1.26 e-5$ & & & & & & \\
\hline Two element & 15.00 & $7.86 e-4$ & 10.00 & $1.57 e-6$ & & & & \\
\hline Four element & 15.00 & $1.26 e-5$ & 10.00 & $1.57 e-6$ & 15.00 & $7.86 e-4$ & 20.00 & $1.00 e-7$ \\
\hline \multicolumn{9}{|c|}{$0.5 \%$ noise in natural frequency and $5.0 \%$ noise in mode shape data } \\
\hline Single element & 9.14 & $1.11 e-3$ & & & & & & \\
\hline Two element & 9.73 & $1.06 e-3$ & 15.20 & $1.11 e-3$ & & & & \\
\hline Four element & 8.46 & $8.40 e-4$ & 14.41 & $6.40 e-3$ & 9.40 & $4.25 e-2$ & 19.47 & $5.96 e-3$ \\
\hline \multicolumn{9}{|c|}{$1.0 \%$ noise in natural frequency and $10.0 \%$ noise in mode shape data } \\
\hline Single element & 11.10 & $7.80 e-3$ & & & & & & \\
\hline Two element & 11.87 & $9.80 e-1$ & 14.07 & $2.81 e-3$ & & & & \\
\hline Four element & 13.66 & $1.20 e-1$ & 13.81 & $8.59 e-2$ & 10.30 & $6.56 e-2$ & 20.43 & $9.76 e-1$ \\
\hline
\end{tabular}

detected and fairly quantified all true damage locations. Further, from the tabulated results it is observed that the standard deviation values are significantly less in comparison to actual damages in all the simulated runs which indicates the robustness of the present algorithm.

3.3. Damage Detection of a Space Frame Structure. The same algorithm is used to detect damages in a 5-storey steel space frame structure as shown in Figure 9. The cross sections for beam as well as column are considered as $25.0 \times 6.0 \mathrm{~mm}^{2}$. The dimensions are shown in Figure 9. Young's modulus and mass density of the beam considered as $200 \times 10^{9} \mathrm{~N} / \mathrm{m}^{2}$ and $7800 \mathrm{~kg} / \mathrm{m}^{3}$, respectively.

Modal analysis is conducted using finite element model to generate natural frequency and mode shape. Nine random damage cases as shown in Table 10 are considered for the purpose of demonstration. From numerical experimentation, it is observed that few false damage locations are produced by the present algorithm using first six natural frequencies and corresponding mode shapes. Therefore, first nine natural frequencies corresponding to translational vibration modes and corresponding mode shapes are used for this study. The size of solution archive is taken as 90. The value of $r$ and $C$ are fixed, respectively, to 5 and 0.001 . The corresponding value of $q$ is calculated as 0.0167 . Value of remaining parameters is kept similar to previous section. The maximum iteration per experiment is fixed at 5000 in this case. The obtained results for proposed damage detection methods are shown in Table 11.

From the Table 11, it is clear that the proposed methodology can accurately detect and quantify the damaged scenarios when noise free modal parameters are available. However, for noisy natural frequency and mode shape data it can be seen that the error associated with proposed algorithm in detecting damage is below $11 \%$ for noise level of $0.50 \%$ in
TABLE 10: Damage conditions to study the frame.

\begin{tabular}{lc}
\hline Case & Description \\
\hline $\mathrm{H} 1$ & $20 \%$ damage at element 3 \\
$\mathrm{H} 2$ & $10 \%$ damage at element 18 \\
$\mathrm{H} 3$ & $15 \%$ damage at element 27 \\
$\mathrm{H} 4$ & $\mathrm{H} 1+30 \%$ damage at element 22 \\
$\mathrm{H} 5$ & $\mathrm{H} 1+\mathrm{H} 3$ \\
$\mathrm{H} 6$ & $\mathrm{H} 2+25 \%$ damage at element 23 \\
$\mathrm{H} 7$ & $\mathrm{H} 2+\mathrm{H} 5$ \\
$\mathrm{H} 8$ & $\mathrm{H} 4+20 \%$ damage at element 32 \\
H9 & $\mathrm{H} 3+\mathrm{H} 6$ \\
\hline
\end{tabular}

frequency measurement and 5.0\% in mode shape measurement and below 20\% for noise level of $1.0 \%$ in frequency measurement and $10.0 \%$ in mode shape measurement. Thus, in summary, it can be stated that the magnitude of errors increase with the increase in the noise level and its magnitude never exceeds $20 \%$ for this particular structure with the considered noise levels. It is also true that, degree of accuracy increases if less number of damaged elements exists. However, it is noticed that accuracy increases apparently with more number of damaged element in some cases, such as for $\mathrm{H} 2$ and $\mathrm{H} 4$ cases. To understand such discrepancies in predictions, results are presented in graphical form in Figure 10 for all structural members for $\mathrm{H} 2$ and $\mathrm{H} 4$ cases.

The number of false predictions is more in double element damage case (H4) than that in single element damage case (H2). Results are plotted only for two cases, that is, for actual damage and for a higher percentage of noise (1\% and $10 \%$ noise in frequency and mode shape data, resp., in this case) in order to avoid clumsiness in graphical results. Similar 
TABLE 11: Multiple damage detection in space frame structure.

\begin{tabular}{|c|c|c|c|c|c|c|c|c|}
\hline \multirow[t]{2}{*}{ Damage case } & \multirow{2}{*}{$\begin{array}{c}\text { Element number } \\
\text { Percentage of noise included }\end{array}$} & \multirow{2}{*}{ Actual damage } & \multicolumn{3}{|c|}{ Detected damage } & \multicolumn{3}{|c|}{ Percentage error } \\
\hline & & & 0 & 5 & 10 & 0 & 5 & 10 \\
\hline $\mathrm{H} 1$ & 3 & 20 & 20.00 & 18.67 & 17.96 & 0.00 & 6.65 & 10.20 \\
\hline $\mathrm{H} 2$ & 18 & 10 & 10.00 & 9.28 & 11.92 & 0.00 & 7.20 & 19.20 \\
\hline $\mathrm{H} 3$ & 27 & 15 & 15.00 & 14.26 & 13.22 & 0.00 & 4.93 & 11.87 \\
\hline \multirow{2}{*}{$\mathrm{H} 4$} & 3 & 20 & 20.00 & 18.41 & 18.62 & 0.00 & 7.95 & 6.90 \\
\hline & 22 & 30 & 30.00 & 28.86 & 27.50 & 0.00 & 3.80 & 8.33 \\
\hline \multirow{2}{*}{ H5 } & 3 & 20 & 20.00 & 21.56 & 17.86 & 0.00 & 7.80 & 10.70 \\
\hline & 27 & 15 & 15.00 & 14.69 & 12.84 & 0.00 & 2.07 & 14.40 \\
\hline \multirow{2}{*}{ H6 } & 18 & 10 & 10.00 & 9.50 & 9.03 & 0.00 & 5.00 & 9.70 \\
\hline & 23 & 25 & 25.00 & 23.46 & 29.53 & 0.00 & 6.16 & 18.12 \\
\hline \multirow{3}{*}{ H7 } & 3 & 20 & 20.00 & 19.80 & 23.20 & 0.00 & 1.00 & 16.00 \\
\hline & 18 & 10 & 10.00 & 8.93 & 9.34 & 0.00 & 10.70 & 6.60 \\
\hline & 27 & 15 & 15.00 & 14.86 & 17.77 & 0.00 & 0.93 & 18.47 \\
\hline \multirow{3}{*}{ H8 } & 3 & 20 & 20.00 & 18.40 & 18.50 & 0.00 & 8.00 & 7.50 \\
\hline & 22 & 30 & 30.00 & 29.68 & 26.80 & 0.00 & 1.07 & 10.67 \\
\hline & 32 & 20 & 20.00 & 17.94 & 22.72 & 0.00 & 10.30 & 13.60 \\
\hline \multirow{3}{*}{ H9 } & 18 & 10 & 10.00 & 10.80 & 10.80 & 0.00 & 8.00 & 8.00 \\
\hline & 23 & 25 & 25.00 & 26.70 & 23.30 & 0.00 & 6.80 & 6.80 \\
\hline & 27 & 15 & 15.00 & 14.60 & 12.10 & 0.00 & 2.67 & 19.33 \\
\hline
\end{tabular}

*Values indicate the added noise level in mode shapes. The noise level in natural frequency is taken as one tenth of that of mode shapes.

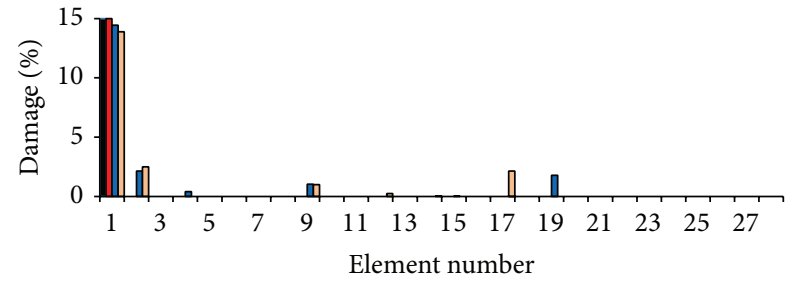

Actual damage

$\square$ Clean data

$0.5 \%$ noise in frequency and $5 \%$ noise in mode shape

$\square 1 \%$ noise in frequency and $10 \%$ noise in mode shape

(a) Single element damage detection case

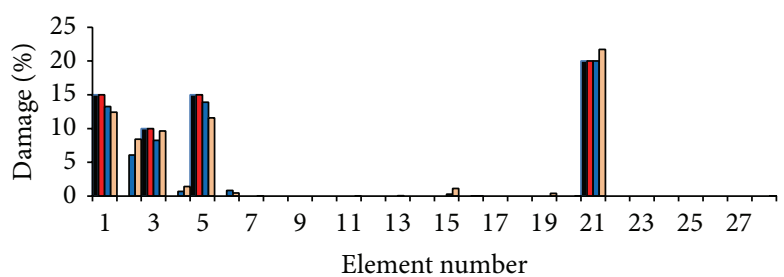

Actual damage

$\square$ Clean data

$\square 0.5 \%$ noise in frequency and $5 \%$ noise in mode shape

$\square 1 \%$ noise in frequency and $10 \%$ noise in mode shape

(c) Four-element damage detection case

FIgURE 8: Damage detection results for 3-bay and 4-storey frame structure. 


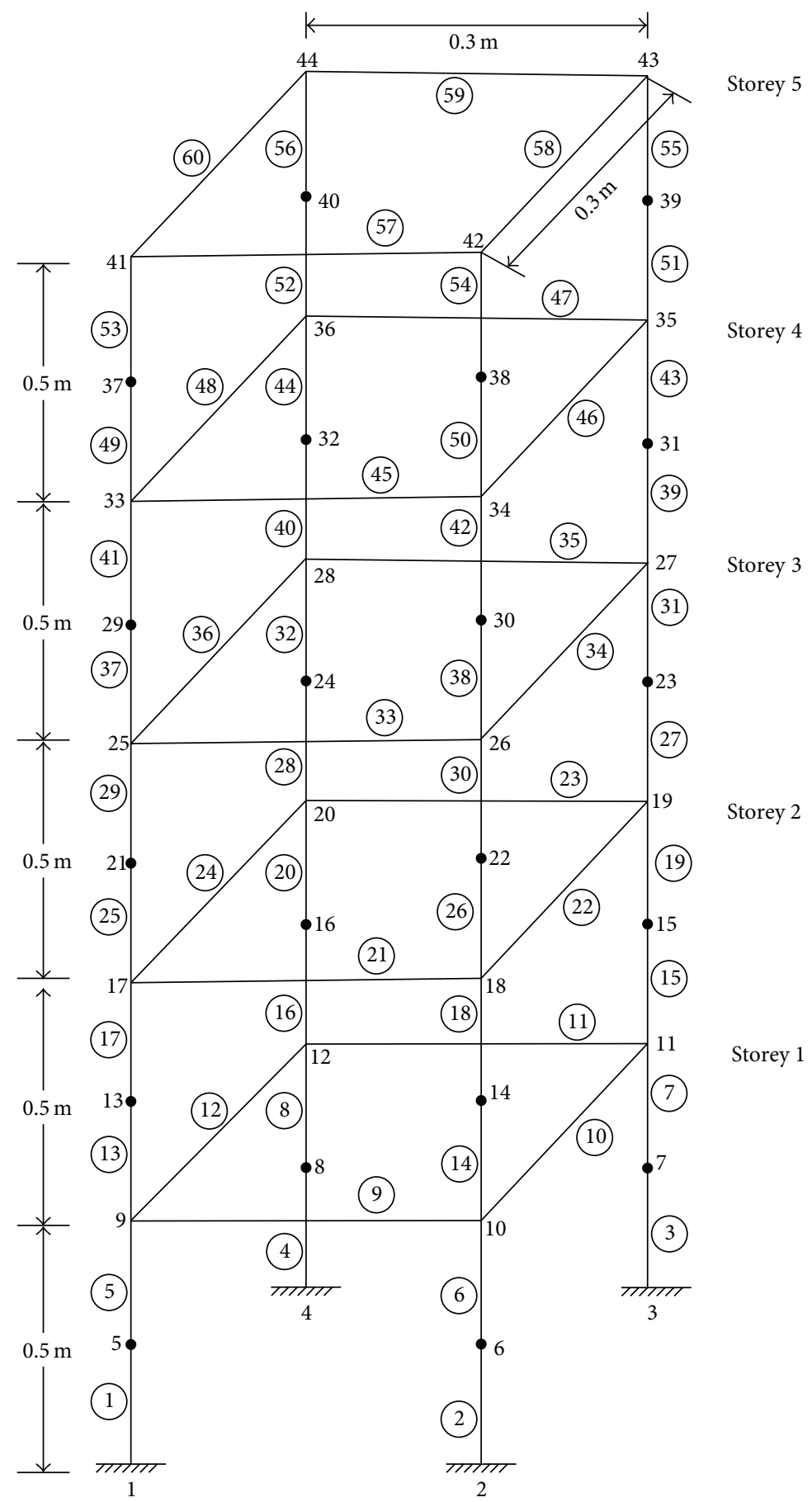

Figure 9: Space frame model.

observations are noticed for other cases also which has not been graphically represented to avoid repetitions.

\section{Conclusion}

A simple but robust damage detection methodology is presented to determine the locations and amount of damages in structures using continuous ant colony optimization algorithm. The algorithm is tested with a laboratory tested data. Further, the effectiveness of the algorithms is studied with cantilever beam model, a 3-bay 4-storey plane frame model, and a five-storey space frame model. The parameters used in $\mathrm{ACO}_{\mathrm{R}}$ algorithm are tuned to optimum values and care is taken to avoid local minima and initial imperfect pheromone depositions leading to preferential building of concentration to suboptimal results. The proposed damage detection method is found to be equally successful regardless of the damage location and extent of damage. 


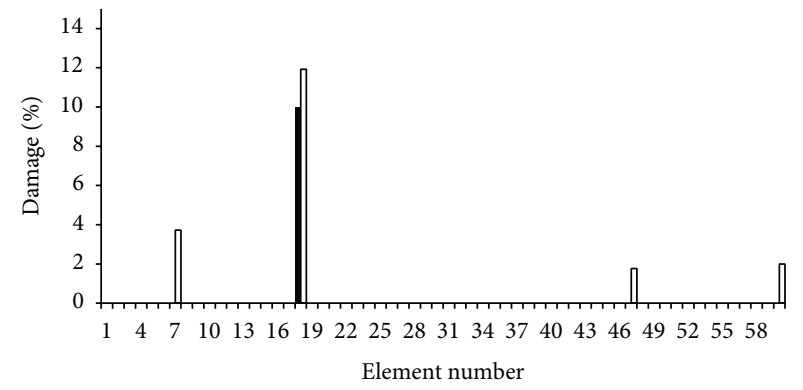

- Actual damage

$\square 1 \%$ noise in frequency and $10 \%$ noise in mode shape

(a) Single element damage case (H2)

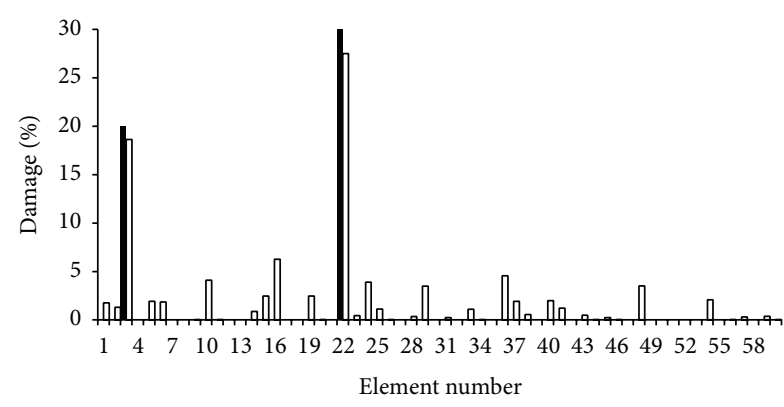

Actual damage

$\square 1 \%$ noise in frequency and $10 \%$ noise in mode shape

(b) Double element damage case (H4)

Figure 10: Damage assessment results for $\mathrm{H} 2$ and $\mathrm{H} 4$ conditions in space frame structure.

\section{Conflict of Interests}

The authors declare that there is no conflict of interests regarding the publication of this paper.

\section{Acknowledgment}

This project is financially supported by Aeronautical Research and Development Board (Structures Panel), Ministry of defense (R\&D), Government of India.

\section{References}

[1] S. W. Doebling, C. R. Farrar, and M. B. Prime, "A summary review of vibration-based damage identification methods," Shock and Vibration Digest, vol. 30, no. 2, pp. 91-105, 1998.

[2] W. Fan and P. Qiao, "Vibration-based damage identification methods: a review and comparative study," Structural Health Monitoring, vol. 10, no. 1, pp. 83-111, 2011.

[3] N. T. Khiem and T. V. Lien, "Multi-crack detection for beam by the natural frequencies," Journal of Sound and Vibration, vol. 273, no. 1-2, pp. 175-184, 2004.

[4] D. P. Patil and S. K. Maiti, "Experimental verification of a method of detection of multiple cracks in beams based on frequency measurements," Journal of Sound and Vibration, vol. 281, no. 1-2, pp. 439-451, 2005.

[5] R. J. Allemang, "The modal assurance criterion: twenty years of use and abuse," Sound and Vibration, vol. 37, no. 8, pp. 14-21, 2003.

[6] C. R. Farrar and G. H. James III, "System identification from ambient vibration measurements on a bridge," Journal of Sound and Vibration, vol. 205, no. 1, pp. 1-18, 1997.

[7] O. S. Salawu and C. Williams, "Bridge assessment using forcedvibration testing," Journal of Structural Engineering, vol. 121, no. 2, pp. 161-173, 1995.

[8] V. Meruane and W. Heylen, "Damage detection with parallel genetic algorithms and operational modes," Structural Health Monitoring, vol. 9, no. 6, pp. 481-496, 2010.

[9] L. Yu and P. Xu, "Structural health monitoring based on continuous ACO method," Microelectronics Reliability, vol. 51, no. 2, pp. 270-278, 2011.
[10] R. R. Tripathy and D. Maity, "Damage assessment of structures from changes in curvature damage factor using artificial neural network," Indian Journal of Engineering \& Materials Sciences, vol. 11, no. 5, pp. 369-377, 2004.

[11] M. Mehrjoo, N. Khaji, H. Moharrami, and A. Bahreininejad, "Damage detection of truss bridge joints using Artificial Neural Networks," Expert Systems with Applications, vol. 35, no. 3, pp. 1122-1131, 2008.

[12] J.-H. Park, J.-T. Kim, D.-S. Hong, D.-D. Ho, and J.-H. Yi, "Sequential damage detection approaches for beams using timemodal features and artificial neural networks," Journal of Sound and Vibration, vol. 323, no. 1-2, pp. 451-474, 2009.

[13] V. Vallabhaneni and D. Maity, "Application of radial basis neural network on damage assessment of structures," Procedia Engineering, vol. 14, pp. 3104-3110, 2011.

[14] D. Maity and R. R. Tripathy, "Damage assessment of structures from changes in natural frequencies using genetic algorithm," Structural Engineering and Mechanics, vol. 19, no. 1, pp. 21-42, 2005.

[15] B. Sahoo and D. Maity, "Damage assessment of structures using hybrid neuro-genetic algorithm," Applied Soft Computing Journal, vol. 7, no. 1, pp. 89-104, 2007.

[16] M.-T. Vakil-Baghmisheh, M. Peimani, M. H. Sadeghi, and M. M. Ettefagh, "Crack detection in beam-like structures using genetic algorithms," Applied Soft Computing, vol. 8, no. 2, pp. 1150-1160, 2008.

[17] H. Liu, K. Xin, and Q. Qi, "Study of structural damage detection with multi-objective function genetic algorithms," Procedia Engineering, vol. 12, pp. 80-86, 2011.

[18] A. Majumdar, D. K. Maiti, and D. Maity, "Damage assessment of truss structures from changes in natural frequencies using ant colony optimization," Applied Mathematics and Computation, vol. 218, no. 19, pp. 9759-9772, 2012.

[19] A. Majumdar, A. De, D. Maity, and D. K. Maiti, "Damage assessment of beams from changes in natural frequencies using ant colony optimization," Structural Engineering and Mechanics, vol. 45, no. 3, pp. 387-406, 2013.

[20] B. Nanda, A. Majumdar, D. Maity, and D. K. Maiti, "Performance comparison among vibration based indicators in damage identification of structures," Applied Mechanics and Materials, vol. 592-594, pp. 2081-2085, 2014.

[21] O. Begambre and J. E. Laier, "A hybrid particle swarm optimization: simplex algorithm (PSOS) for structural damage 
identification," Advances in Engineering Software, vol. 40, no. 9, pp. 883-891, 2009.

[22] R. Perera, S.-E. Fang, and A. Ruiz, "Application of particle swarm optimization and genetic algorithms to multiobjective damage identification inverse problems with modelling errors," Meccanica, vol. 45, no. 5, pp. 723-734, 2010.

[23] B. Nanda, D. Maity, and D. K. Maiti, "Vibration based structural damage detection technique using particle swarm optimization with incremental swarm size," International Journal of Aeronautical and Space Sciences, vol. 13, no. 3, pp. 323-331, 2012.

[24] S. C. Mohan, D. K. Maiti, and D. Maity, "Structural damage assessment using FRF employing particle swarm optimization," Applied Mathematics and Computation, vol. 219, no. 20, pp. 10387-10400, 2013.

[25] B. Nanda, D. Maity, and D. K. Maiti, "Crack assessment in frame structures using modal data and unified particle swarm optimization," Advances in Structural Engineering, vol. 17, no. 5, pp. 747-766, 2014.

[26] B. Nanda, D. Maity, and D. K. Maiti, "Modal parameter based inverse approach for structural joint damage assessment using unified particle swarm optimization," Applied Mathematics and Computation, vol. 242, pp. 407-422, 2014.

[27] M. Dorigo and T. Stutzle, Ant Colony Optimization, The MIT Press, Cambridge, Mass, USA, 2004.

[28] K. Socha and M. Dorigo, "Ant colony optimization for continuous domains," European Journal of Operational Research, vol. 185, no. 3, pp. 1155-1173, 2008.

[29] S. Madadgar and A. Afshar, "An improved continuous ant algorithm for optimization of water resources problems," Water Resources Management, vol. 23, no. 10, pp. 2119-2139, 2009.

[30] M. Mohamad, M. O. Tokhi, and M. Omar, "Continuous ant colony optimisation for active vibration control of flexible beam structures," in Proceedings of the IEEE International Conference on Mechatronics (ICM '11), pp. 803-808, April 2011.

[31] M. Abachizadeh and M. Tahani, "Optimizing laminated composites using ant colony algorithms," in Ant Colony Optimization-Methods and Applications, A. Ostfeld, Ed., InTech, 2011.

[32] Y. Hajizadeh, M. Christie, and V. Demyanov, "Ant colony optimization for history matching and uncertainty quantification of reservoir models," Journal of Petroleum Science and Engineering, vol. 77, no. 1, pp. 78-92, 2011.

[33] T. Warren Liao and P. C. Chang, "Impacts of forecast, inventory policy, and lead time on supply chain inventory-a numerical study," International Journal of Production Economics, vol. 128, no. 2, pp. 527-537, 2010.

[34] M. Khalidji, M. Zeiaee, A. Taei, M. R. Jahed-Motlagh, and H. Khaloozadeh, "Dynamically weighted continuous ant colony optimization for biobjective portfolio selection using value-atrisk," in Proceedings of the 3rd Asia International Conference on Modelling and Simulation (AMS '09), pp. 230-235, Bali, India, May 2009.

[35] H. Movahedipour, "Application of continuous $\mathrm{ACO}_{R}$ to neural network training: direction of arrival problem," in Ant Colony Optimization-Methods and Applications, A. Ostfeld, Ed., pp. 159-178, InTech, 2011.

[36] G. Leguizamón and C. A. C. Coello, "An alternative $\mathrm{ACO}_{\mathrm{R}}$ algorithm for continuous optimization problems," in Swarm Intelligence, M. Dorigo, M. Birattari, G. A. D. Caro et al., Eds., pp. 48-59, Springer, Berlin, Germany, 2010.
[37] T. Liao, M. A. M. de Oca, D. Aydin, T. Stützle, and M. Dorigo, "An incremental ant colony algorithm with local search for continuous optimization," in Proceedings of the 13th Annual Genetic and Evolutionary Computation Conference (GECCO '11), pp. 125-132, July 2011.

[38] J. Xiao and L. Li, "A hybrid ant colony optimization for continuous domains," Expert Systems with Applications, vol. 38, no. 9, pp. 11072-11077, 2011.

[39] T. W. Liao, R. J. Kuo, and J. T. Hu, "Hybrid ant colony optimization algorithms for mixed discrete-continuous optimization problems," Applied Mathematics and Computation, vol. 219, no. 6, pp. 3241-3252, 2012.

[40] M. I. Friswell, J. E. T. Penny, and S. D. Garvey, "Parameter subset selection in damage location," Inverse Problems in Engineering, vol. 5, no. 3, pp. 189-215, 1997.

[41] T. Marwala, Finite Element Model Updating Using Computational Intelligence Techniques: Applications to Structural Dynamics, Springer, 2010.

[42] H. Hao and Y. Xia, "Vibration-based damage detection of structures by genetic algorithm," Journal of Computing in Civil Engineering, vol. 16, no. 3, pp. 222-229, 2002.

[43] L. Yu and P. Xu, "An ACO-based algorithm for structural health monitoring," in Proceedings of the Prognostics and System Health Management Conference (PHM '10), IEEE, Macau, China, January 2010. 

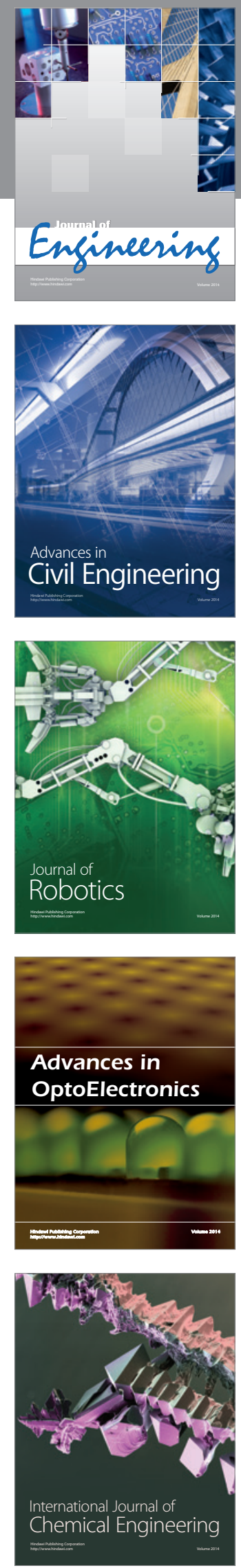

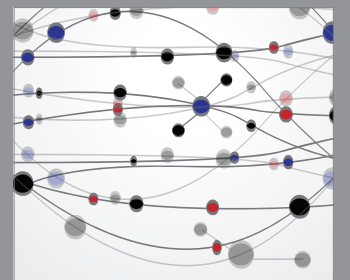

The Scientific World Journal
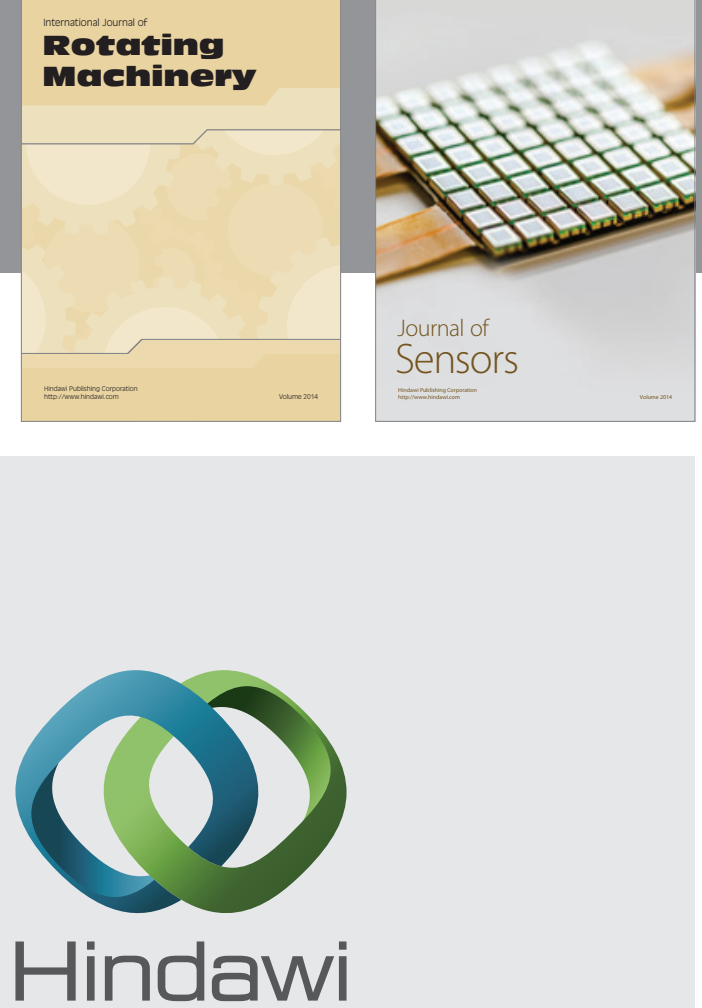

Submit your manuscripts at http://www.hindawi.com
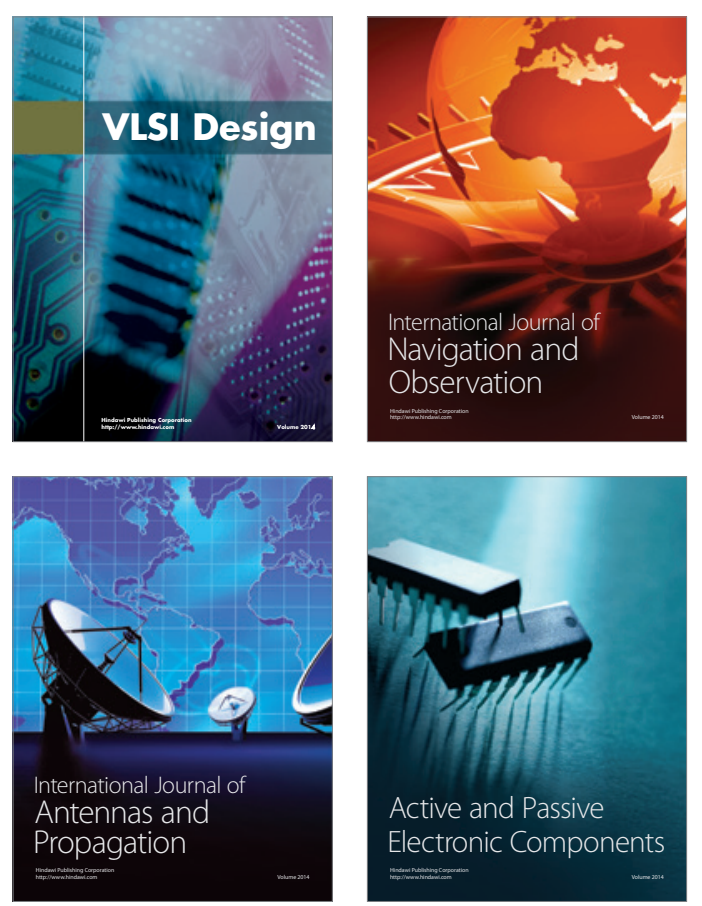
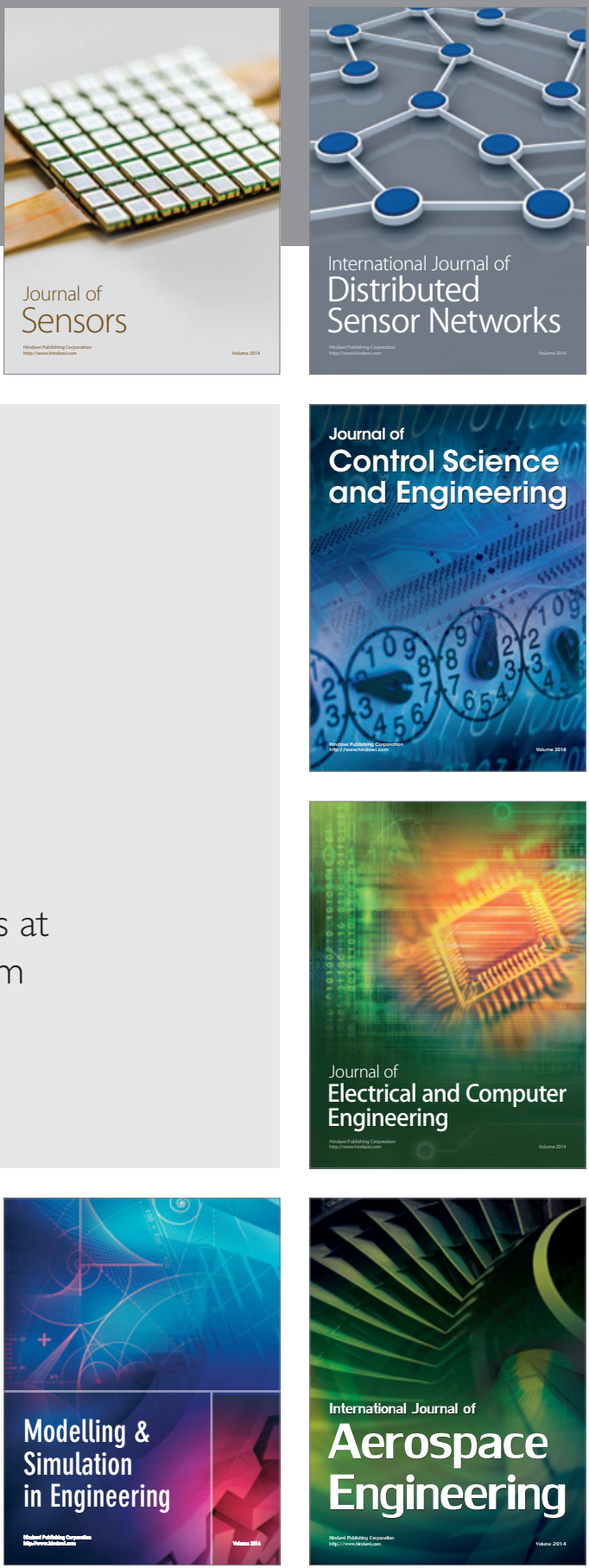

Journal of

Control Science

and Engineering
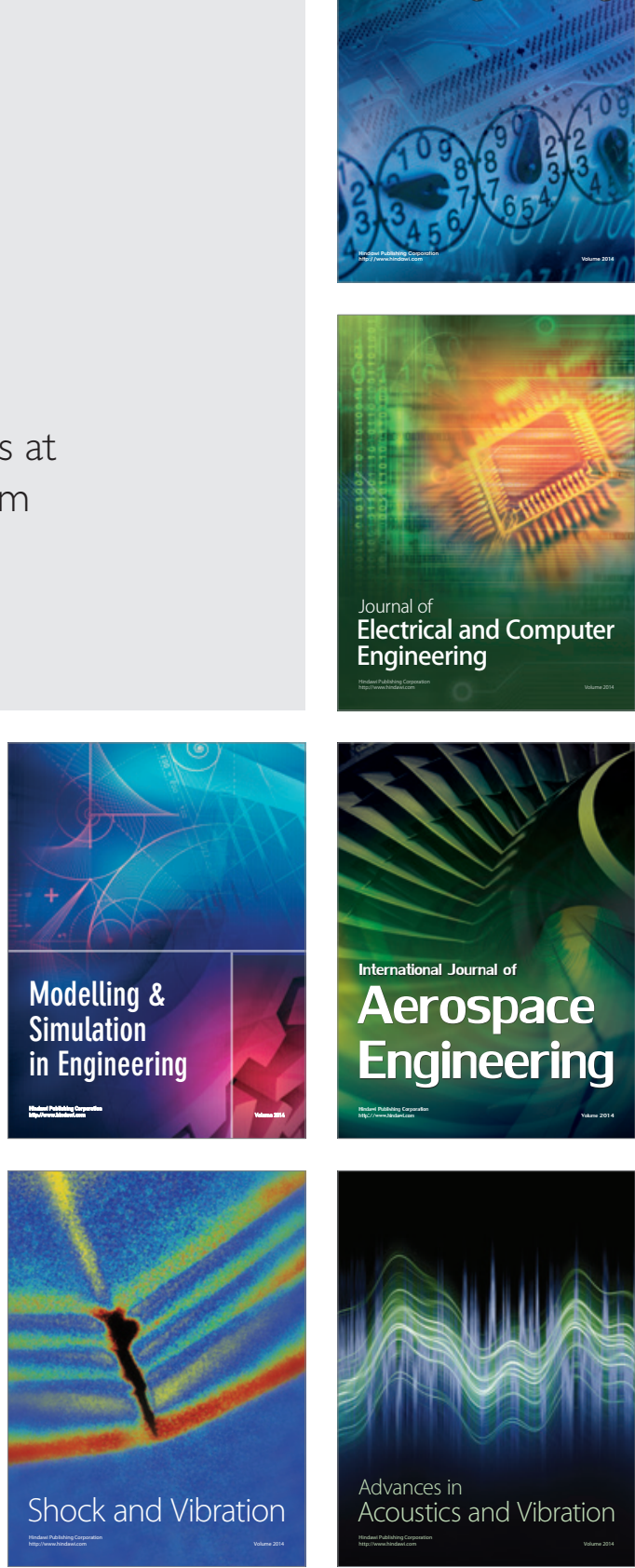